https://doi.org/10.48009/2_iis_2007_26-31

\title{
USER ASSESSMENT OF AN ADVISORY SERVICE SYSTEM: USE OF THE E-S-QUAL INSTRUMENT
}

\author{
Craig K. Tyran, Western Washington University, craig.tyran@wwu.edu \\ Steven C. Ross, Western Washington University, steve.ross@wwu.edu
}

\begin{abstract}
MIS faculty members at a public university have developed a prototype academic advising support system (AASS). To facilitate user assessment of the system, an instrument that measures service quality for electronic services was modified and administered. Results from the survey of 63 students found that the instrument was suitable for a service-based system such as AASS. The factor of efficiency was considered to be the most significant electronic service attribute related to perceived value of the system. The implications of the study are discussed.
\end{abstract}

Keywords: Academic advising, electronic service quality, E-S-QUAL, service quality, SERVQUAL, support systems.

\section{INTRODUCTION}

Academic advising is an important service provided by institutions of higher education. At our institution, a web-based information system to support academic advising has been created and evaluated. A primary purpose of this manuscript is to describe the use of the electronic service quality (E-S-QUAL) instrument developed by Parasuraman, et al. [12] to assess the service quality provided by the system. In the first portion of the manuscript, we provide an overview of academic advising and advising practices at our institution. We also summarize the assessment of advising services in our academic department and describe the system that was subsequently developed to support our advising services. The second portion of the manuscript describes the process used to adapt and evaluate the E-S-QUAL instrument for a portion of the user assessment (UA). The E-S-QUAL instrument offered a useful framework for approaching UA from the perspective of service quality and helped us to evaluate the system.

\section{ACADEMIC ADVISING AND SYSTEM SUPPORT}

\section{Academic Advising}

At most universities, students must satisfy university and major requirements - usually embodied in course work - to qualify for a degree. Prescribed coursework often includes options (electives) as well as sequences (prerequisite courses). Determining an acceptable program of study can be challenging, since most students enter academia from secondary education programs that have highly structured curricula. Academic advising refers to the practice of assisting students with this process as they determine a program of study that will meet their intellectual and career interests and will satisfy university and academic major graduation requirements.

The quality of academic advising services can have important implications for universities, including student retention and graduation rates [4]. The topic of academic advising has been the subject of much research. Useful general references on academic advising include Gordon [5] and publications by the National Academic Advising Association (e.g., [9]).

There are several organizational models for advising [8]. The most common is the "faculty" model in which faculty members deliver advising services to students. These interactions include both program planning as well as career and specialty choice. While there are benefits to this approach, such as the development of student/faculty relationships and low cost to the institution, there can also be problems related to low faculty commitment and inconsistent advising quality [8].

As discussed by Bellenger and Bellenger [1], the benefits that may accrue from an automated system to support advising services, include time efficiency, cost reduction, and accuracy. An automated system might solve several other problems as well, such as information disappearance, information delay, and information distortion. Other authors [see, e.g., 2, 6] also discuss the potential benefits of technologybased solutions.

\section{Advising Practices at Western Washington University}

Western Washington University (WWU) is a regional public university located in the Western United States. The Department of Decision Sciences (DSCI), a unit of the College of Business and Economics, offers a degree in Business Administration with concentrations in MIS, Operations Management, and Manufacturing Management. Neither department nor college has a centralized advising function. A student who has applied for admission is informed by the college office whether he or she has been accepted - 
based almost entirely on whether the minimum qualifications have been met. All academic advising is handled by the department housing the student's major. Each DSCI student is assigned to a faculty advisor with whom the student is expected, but not required, to meet. The faculty are expected to address general curriculum questions and to help the students develop a plan of study that will address each student's academic interests and lead to timely graduation.

Among the departmental faculty, there has been a general sense that advising services could be improved for DSCI students. For example, each year some students encounter problems as they approach graduation due to poor class schedule planning. In some cases, the student has failed to meet with an advisor for plan review and has made poor decisions regarding scheduling. In other cases, an advisor approved a plan that contained flaws in course sequencing or elective choice. Also, there has been occasional grumbling from students about problems regarding the responsiveness or attentiveness of a faculty advisor.

\section{Assessment of Advising Services}

To investigate academic advising at WWU, the authors employed a version of the SERVQUAL survey instrument $[10,11]$ to determine students' expectations and perceptions of the department's delivery of academic advising [14]. In addition to the survey, an audit of a sample of advising plans for students was conducted. The key findings from the assessment can be summarized as follows:

- Many students were not meeting with their advisors.

- Mistakes were being made during advising.

- Information resources and reliability were considered to be the most important dimensions for academic advising service quality.

- Ratings for the quality of advising services were generally good, but perceptions of actual service were not as high as expectations.

Based on this information, the department saw the potential to improve academic advising services using an automated support system. The survey findings guided the design and development of an information system to support advising.

\section{The Academic Advising Support System}

The department created a prototype system named the Academic Advising Support System (AASS). One of the key advising challenges uncovered in the assessment of advising services concerned the development of a student's "Plan of Study." The plan of study contains a list of the required and elective courses for a specific major, and records the student's choices as to which quarter he or she intends to enroll in a given course.

The AASS was developed to provide a systematic and easy-to-use way to help students and their advisors establish a plan that will satisfy the College's curriculum requirements - both in terms of coverage (all the necessary courses and credits) as well as sequence. To use the web-based system, a student logs on and indicates a choice of major and the year in which studies will commence. A matrix is then presented, with required and elective courses on the rows and academic quarters in the columns. Radio buttons are clicked on a row to indicate the quarter in which the student intends to take the course. When completed, the student clicks a "Submit" button. After a study plan is submitted, the system conducts several error checks and then provides a detailed report that indicates any problems with the study plan (e.g., prerequisites not met, missing courses, etc.).

The student may "revise and resubmit" as many times as necessary until an error-free plan is achieved. All study plan information is stored in the system for future use. The system provides an environment in which a student may explore alternative scheduling options. If a student wishes to evaluate the impact of a schedule change, he or she simply changes the planned date of the relevant courses and receives a new report. A more comprehensive description of the system, including screen captures of the user interface, may be found in [13].

With a prototype in place, the department undertook user assessment (UA) of the system. The remainder of this manuscript discusses the process that we used to adapt and utilize a well-known service quality survey instrument for a portion of the UA. The method that we followed provides a useful framework for approaching UA for an advisory service-based system from the perspective of service quality.

\section{USER ASSESSMENT OF A SERVICE-BASED SYSTEM}

The SERVQUAL instrument played a useful role in identifying key areas for requirements specification for the AASS. Following the implementation of the service-based system, the next step was to develop an instrument to support the user assessment of the system and to identify and evaluate the general aspects of electronic-based service quality for the AASS system. For purposes of this study, a survey instrument developed by the creators of SERQUAL was used. 
Entitled E-S-QUAL (for Electronic Service Quality), this instrument was designed to measure service quality for WWW-based information systems [12]. The instrument includes 22 survey items to assess the following four factors of system service: efficiency, system availability, privacy, and order fulfillment. Although the instrument was originally developed for the online retail business context, the survey items for the first three factors appear to be applicable to an advisory service oriented system such as AASS. One of the goals of this study was to explore the suitability of E-S-QUAL for the assessment of AASS. Another goal was to identify priorities for ongoing system development by examining the factors of electronic service that were most strongly related to user perceptions of system value.

Some modifications were made to the E-S-QUAL instrument for purposes of our study. First, the seven order fulfillment items were removed from the instrument, as this section of the survey is not applicable to an advisory or decision-support system. Also, as suggested by authors of the instrument, the wording of several of the E-S-QUAL instrument items was modified slightly to be appropriate for the academic advising context. The fifteen items on the modified E-S-QUAL survey used for this study are provided in Table 1.

In addition to the adapted version of the E-S-QUAL instrument, our survey also included a four-item scale to assess perceived value for the system. This scale was included to serve as the dependent variable for regression analysis. These survey items were closely based on a scale used and validated by Parasuraman, et al. [12]. The survey also included an open-ended question that provided an opportunity for the respondents to make comments and suggestions for improvement.

\section{SURVEY METHODOLOGY AND FINDINGS}

\section{Sample}

The survey sample included all students who had declared an academic concentration in the Department of Decision Sciences. A total of 86 students were surveyed, resulting in 63 usable surveys. At the time they used and assessed the system, the students were beginning their third year of academic studies. The respondents represented three areas of academic concentration: Information Systems (45\% of respondents), Operations Management (30\%), and Manufacturing and Supply Chain Management (25\%). Most of the respondents indicated familiarity with their concentration area, as $99 \%$ of the students reported that they had knowledge of the required courses for their concentration and 63\% had knowledge of the elective courses.

\section{Method}

All subjects were provided with a brief lecture overview of the AASS before using the system. Subjects were then given instructions for using the system and were asked to work on their own to develop a plan of study using the system. Following the use of the system, the subjects completed the survey questionnaire. Subjects were provided with nominal class credit to use the system and complete the survey. The survey data associated with each submission was inspected for quality (e.g., any surveys that were submitted with numerous incomplete entries or the same value for a large portion of the survey items were not used for analysis).

\section{Factor Analysis}

To explore the factor structure of the E-S-QUAL instrument, the data reduction approach described by Parasuraman, et al. [12] was used for the factor analysis. Specifically, the scores for each item on the ES-QUAL instrument were factor analyzed using the principal components factoring procedure followed by an oblique rotation using oblimin (with Kaiser normalization). All factors with eigenvalues greater than one were retained.

The sample size used for this study was relatively small for a factor analysis [3]. Research by Guadagnoli and Velicer [7] indicates that items with higher loadings are more likely to result in stable factors for smaller sample sizes. Hence, a high threshold for factor loading was used to determine which items to keep for additional analysis. For this study, factor loadings over 0.6 were considered to be significant. Based on this criterion, the original set of fifteen items was reduced to twelve items. These items loaded on three factors and explained $69 \%$ of the variance (see Table 1).

The general structure of the original E-S-QUAL instrument appears to be appropriate for the advisory service type of system used in this study, as each of the remaining twelve items loaded onto the factor that would be expected from the original E-S-QUAL instrument [12]. The factors of efficiency, system availability, and privacy emerged from the factor analysis. As indicated in Table 1, based on the factor structure, the convergent and discriminant validity of the three factors is good. Also, as shown in Table 2, the reliability of the three resulting scales is strong with Cronbach alpha statistics ranging from 0.870.94 . 
Table 1. Factor Loadings for the E-S-QUAL Instrument adapted for Academic Advising Support System

\begin{tabular}{|l|c|c|c|}
\hline $\begin{array}{l}\text { E-S-QUAL Factor Dimension (adapted from } \\
{[\mathbf{1 2}] \text { - Illustrative Portion of Survey Item }}\end{array}$ & Efficiency & $\begin{array}{c}\text { Factor Loadings } \\
\text { System } \\
\text { Availability }\end{array}$ & Privacy \\
\hline Efficiency - Easy to enter information. & .80 & & \\
\hline $\begin{array}{l}\text { Efficiency - Easy to navigate anywhere on the sys- } \\
\text { tem. }\end{array}$ & .75 & & \\
\hline $\begin{array}{l}\text { Efficiency - Enables me to prepare and evaluate my } \\
\text { study plan quickly. }\end{array}$ & .85 & & \\
\hline $\begin{array}{l}\text { Efficiency - Portion of system used to enter infor- } \\
\text { mation is well organized. }\end{array}$ & .65 & & \\
\hline Efficiency - WWW pages for system load fast. & $\dagger$ & & \\
\hline Efficiency - System was easy to use. & .71 & & \\
\hline Efficiency - User can get onto the system quickly. & $\dagger$ & & \\
\hline $\begin{array}{l}\text { Efficiency - Portion of system use for reporting } \\
\text { information back to me is well organized. }\end{array}$ & .79 & & \\
\hline $\begin{array}{l}\text { System Availability - System is always available } \\
\text { for me to use. }\end{array}$ & & & \\
\hline $\begin{array}{l}\text { System Availability - System launches and runs } \\
\text { right away. }\end{array}$ & & -.91 & \\
\hline System Availability - System does not crash. & & -.84 & \\
\hline $\begin{array}{l}\text { System Availability - Pages on the system do not } \\
\text { freeze after I enter my information. }\end{array}$ & & & \\
\hline $\begin{array}{l}\text { Privacy - System protects information about my } \\
\text { study plan. }\end{array}$ & & & \\
\hline $\begin{array}{l}\text { Privacy - System does not share my study plan } \\
\text { information with others. }\end{array}$ & & $\mathbf{9 0}$ \\
\hline $\begin{array}{l}\text { Privacy - System protects information about my } \\
\text { university ID number. }\end{array}$ & & $\mathbf{1 7 . 0}$ & $\mathbf{1 3 . 0}$ \\
\hline Eigenvalues & & & \\
\hline \% of Variance & & & \\
\hline
\end{tabular}

Notes: 1. The first column in the table above provides a portion of each survey question. The survey questions used for the study followed the format used by Parasuraman, et al. [12].

2. Scale items were on a Likert scale ranging from 1 ("Strongly Disagree”) to 7 (“Strongly Agree”); higher values reflect a more favorable perception of the information system.

3. Similar to Parasuraman, et al. [12], the factor analysis used principle component analysis as the extraction method and oblimin (with Kaiser normalization) as the rotation method.

4. Only factor loadings over .60 are shown. $\dagger$ indicates factor loading $<.60$ for an item on the original ES-QUAL scale.

5. $\mathrm{N}=63$.

\section{Results of the System Assessment}

The mean values and the correlation matrix for the scales are shown in Table 2 . The mean values range from 5.41 to 6.17 on a 1-7 point Likert scale (higher values reflect more favorable perceptions of the system). The highest rating was for system availability, but all the mean scores indicate positive feedback from the users. Based on these results, it appears that the AASS provides positive benefit to the intended users. Comments on the open-ended survey question offered ideas for features that can be added or enhanced in future versions of the system. These fea- tures, including a direct link to the university's academic records system and a stronger authentication process, would directly improve efficiency and privacy aspects of the system.

\section{Regression Analysis}

In order to assess the extent to which each of the three factors had an impact on the perceived value of the system, a regression analysis was conducted. The independent variables were based on the E-S-QUAL scales for efficiency, system availability, and privacy, 
while the independent variable was based on the perceived value scale discussed earlier.

The regression results are displayed in Table 3. As indicated in Table 3, the R-square for the regression was strong (46\%) and the regression relationship was significant. While the correlations across the independent variables and perceived value were all strong, the regression coefficient corresponding to the efficiency factor was the only factor which was found to be significant for the regression equation. This suggests that the efficiency factor may be relatively more important than the other factors with respect to predicting perceptions about perceived value. This finding is consistent with that of Parasuraman, et al. [12], who found this factor was a key predictor for web-based service quality for large retail organizations.

Table 2. Summary of Scale Statistics and Correlations for Scales used in Regression Analysis

\begin{tabular}{|l|c|c|c|c|}
\hline Scales & $\mathbf{1}$ & $\mathbf{2}$ & $\mathbf{3}$ & $\mathbf{4}$ \\
\hline 1. Efficiency & - & & & \\
\hline 2. System Availability & $.31^{* *}$ & - & & \\
\hline 3. Privacy & $.27^{*}$ & $.35^{* *}$ & - & \\
\hline $4 . \quad$ Perceived Value & $.65^{* * *}$ & $.34^{* *}$ & $.65^{* *}$ & - \\
\hline No. of Items in Scale & 6 & 3 & 3 & 4 \\
\hline Scale Reliability & 0.87 & 0.90 & 0.94 & 0.86 \\
\hline Mean & 5.43 & 6.17 & 5.41 & 5.49 \\
\hline Std Deviation & 0.87 & 0.88 & 1.21 & 0.85 \\
\hline
\end{tabular}

Notes: 1. E-S-QUAL scales for Efficiency, System Availability and Privacy are based on items with factor loadings over 0.60. Scale items were on a Likert scale ranging from 1 ("Strongly Disagree") to 7 ("Strongly Agree"); higher values reflect a more favorable perception of the information system.

2. The "Perceived Value" scale was based on Parasuraman, et al. [12]. Scale items were on a Likert scale ranging from 1 ("Poor") to 7 ("Excellent”); higher values reflect a more favorable perception of the information system.

3. Scale reliability calculated using Cronbach's Alpha.

4. ${ }^{*} \mathrm{p}<.05,{ }^{* *} \mathrm{p}<.01, * * * p<.001$.

5. $\mathrm{N}=63$.

Table 3. Summary of Regression Analysis for Variables Predicting Perceived Value of System

\begin{tabular}{|l|c|c|c|}
\hline Variable & B & \multicolumn{1}{|c|}{ SE B } & $\boldsymbol{\beta}$ \\
\hline Constant & 1.20 & 0.66 & \\
\hline Efficiency & 0.56 & 0.10 & 0.57 *** \\
\hline System Availability & 0.10 & 0.10 & 0.10 \\
\hline Privacy & 0.11 & 0.07 & 0.16 \\
\hline $\boldsymbol{R}^{2}$ & \multicolumn{3}{|c|}{0.46} \\
\hline $\boldsymbol{F}$ & $18.0^{* * *}$ \\
\hline
\end{tabular}

Notes: $\quad 1 .{ }^{*} \mathrm{p}<.05,{ }^{* *} \mathrm{p}<.01,{ }^{* * *} \mathrm{p}<.001$.

2: $\mathrm{N}=63$. 


\section{CONCLUSIONS}

In the assessment of advising services, students identified the dimensions of information resources and reliability as the most important aspects of advising service quality. The AASS was designed to provide useful and accurate information resources on a platform that is reliable both from systems operational as well as data validity points of view. The E-S-QUAL dimension of efficiency corresponds most closely with the reliability construct of SERVQUAL. Although users reported that the system was efficient, improvements to aspects of system efficiency could increase the perceived value of the system.

This study adapted a new survey instrument - E-SQUAL - to assess the service quality for a web-based information system designed to support academic advising services. While the findings for this study are exploratory in nature due to the relatively small sample size, the findings from the factor analysis suggest that the E-S-QUAL instrument may be useful for measuring service quality for an advisory service type of information system, as well as service quality for web-based retail stores.

As one might expect, there are limitations to an exploratory study of this type. First, the sample size was relatively small. A larger sample size will be required to conduct a more complete evaluation of the suitability of the E-S-QUAL instrument to an advisory service system. Second, the subjects for this study had somewhat limited exposure to the AASS. It may be that a study of this type would generate different findings with a more experienced subject pool. Third, the information system used for the study focused on academic advising. There are a variety of different service-based information systems (e.g., library systems, financial planning systems, etc.). It may be that E-S-QUAL is not suitable for every type of system that provides services. Despite its limitations, this study has had practical value for the assessment of the AASS and suggests intriguing questions for future research involving the assessment of service quality for service-based information systems.

\section{REFERENCES}

1. Bellenger, J.E. \& D.N. Bellenger (1987) Guidelines for Computerizing Your Information System for Academic Program Counseling: Dealing with People Problems, NASPA Journal, 24(4), 53-60.

2. Comer, J., Nute, T., \& Rodjak, D. (1991) CASAS: Engineering Software Applications, Information and Software Technology, 33(6), 443450.
3. Comrey, A.L., \& Lee, H.B. (1992) A first course in factor analysis (2nd ed.). Hillsdale, NJ: Erlbaum.

4. Glennen, R.E. (1996) How Advising and Retention of Students Improves Fiscal Stability, NACADA Journal, 16, 38-46.

5. Gordon, V.N. (1994) Academic Advising: An Annotated Bibliography. Westport, CT: Greenwood Press.

6. Grupe, F.H. (2002) An Internet-based Expert System for Selecting an Academic Major, The Internet and Higher Education, 5, 333-344.

7. Guadagnoli, E. \& Velicer, W.F. (1988) Relation of Sample Size to the Stability of Component Patterns, Psychological Bulletin, 103(2), 265275.

8. King, M.C. \& Kerr, T.J. (1995) Organizing and Delivering Academic Advising for First-Year Students, in First-Year Academic Advising: Patterns in the Present, Pathways to the Future (NACADA monograph, M.L. Upcraft \& G.L. Kramer, editors), 35-43.

9. NACADA Journal (2003) Technology and Advising: Annotated Bibliography for research published prior to 1999, https://www.nacada.ksu.edu/Clearinghouse/Rese arch_Related/advtechbib.htm read March 9, 2006.

10. Parasuraman, A., Berry, L.L., \& Zeithaml, V.A. (1991) Refinement and Reassessment of the SERVQUAL Scale, Journal of Retailing, 67(4), 420-450.

11. Parasuraman, A., Zeithaml, V.A. \& Berry, L.L. (1988) SERVQUAL: A Multiple-Item Scale for Measuring Customer Perceptions of Service Quality, Journal of Retailing, 64(1), 12-40.

12. Parasuraman, A., Zeithaml, V.A. \& Malhotra, A. (2005) E-S-QUAL: A Multiple-Item Scale for Assessing Electronic Service Quality, Journal of Service Research, 7(3), 213-233.

13. Tyran, C.K. \& Ross, S.C., (2005) Academic Advising Services for IS Students: What are Student Expectations and What Support Can Technology Provide? Proceedings of International Conference on Informatics Education Research, Las Vegas, NV.

14. Tyran, C.K. \& Ross, S.C., (2006) Service Quality Expectations and Perceptions: Use of the SERVQUAL Instrument for Requirements Analysis, Issues in Information Systems, 7(1), 357-362. 